\title{
Assessing the sampling effort required to estimate $\alpha$ species diversity in the groundfish assemblages of the North Sea
}

\author{
Simon P. R. Greenstreet ${ }^{1, *}$, Gerjan J. Piet ${ }^{2}$ \\ ${ }^{1}$ Fisheries Research Services, Marine Laboratory, PO Box 101, Victoria Road, Aberdeen AB11 9DB, UK \\ ${ }^{2}$ Wageningen IMARES, PO Box 68, 1970 AB IJmuiden, The Netherlands
}

\begin{abstract}
Conserving and restoring biodiversity are key objectives for an ecosystem approach to management in the North Sea, but ecological quality objectives for the groundfish community instead concentrate on restoring size structure. Species richness and diversity estimates are strongly influenced by sampling effort. Failure to account for this has led to the belief that species richness and diversity indices are not adequate indicators of 'state' for the groundfish community. However, adherence to a standard procedure that is robust within respect to sampling effort influence should allow these metrics to perform a state indicator role. The Arrhenius power and Gleason semi-log species-area relationships are examined to determine whether they can provide modelled estimates of species richness at the ICES (International Council for the Exploration of the Sea) rectangle scale. Of these, the Gleason semi-log appears most reliable, particularly when a randomised aggregation process is followed. Aggregation of at least 20 trawl samples is required to provide empirically derived index values that are representative of the communities sampled, and therefore sensitive to drivers of change in these communities. However, given current groundfish survey sampling levels, combining 20 half-hour trawl samples to provide single estimates of species richness and diversity will require considerable aggregation over time and/or space. This can lead to estimates of $\alpha$ or local richness/ diversity becoming inflated through the inclusion of elements of $\beta$ or regional richness/diversity. For the North Sea groundfish assemblage, this occurs when the distance between the focal position and the location of the most distant sample exceeds $49 \mathrm{~km}$.
\end{abstract}

KEY WORDS: Ecosystem approach to management $\cdot$ State indicators $\cdot$ Sample-size dependency Species-area relationships $\cdot \alpha$-diversity $\cdot \beta$-diversity $\cdot$ Management frameworks

- Resale or republication not permitted without written consent of the publisher

\section{INTRODUCTION}

Several policy commitments to protect marine biodiversity, both globally and regionally, underpin the recent moves towards an 'ecosystem approach to management' (EAM) in the North Sea (Greenstreet 2008). The convention for the protection of the marine environment of the north-east Atlantic, OSPAR, deemed the competent authority to develop the EAM, identified 10 key ecological quality issues for the North Sea and requested relevant expert bodies, such as the International Council for the Exploration of the Sea (ICES), to define ecological quality objectives (EcoQOs) for each issue. Developing the EAM along these lines requires indicators that portray the 'state' of dif- ferent components of marine ecosystems (Jennings \& Reynolds 2000, Frid 2003, Garcia \& Cochrane 2005).

Groundfish surveys, carried out for decades in support of traditional fisheries management, provide data on the numbers at length of all species sampled (Heessen 1996, Heessen \& Daan 1996). Such data are ideal for the computation of many multi-species community descriptors (e.g. Washington 1984). Since 'fish communities' was the fifth in OSPAR's list of 10 ecological quality issues (Johnson 2008, Heslenfeld \& Enserink 2008), examining long-term change of different aspects of the North Sea demersal fish community received considerable attention (Greenstreet \& Hall 1996, Hall \& Greenstreet 1996, 1998, Rice \& Gislason 1996, Greenstreet et al. 1999, Jennings et al. 1999, 2002, 
Rogers et al. 1999, Rogers \& Ellis 2000, Piet \& Jennings 2005). Long-term declines in species richness and diversity were revealed (e.g. Greenstreet \& Hall 1996, Rijnsdorp et al. 1996, Greenstreet et al. 1999), and shown to be a result of fishing activity (Greenstreet \& Rogers 2006). Given the political concern over biodiversity, one might have anticipated that the EcoQO for fish communities would address this decline in fish species diversity. Instead, the EcoQO is directed towards restoring the size structure of demersal fish in the North Sea (ICES 2007, Greenstreet 2008). How did this change in focus arise?

When asked by OSPAR to recommend appropriate state indicators to support an EcoQO for Fish Communities, ICES proposed 7 criteria on which to base their judgement (ICES 2001). These criteria, listed in Table 1, place considerable emphasis on the linkage between indicator performance and the anthropogenic activity in question. Species diversity indices performed poorly against several of these criteria, and so were discarded as possible state indicators for the fish community EcoQO (Greenstreet 2008). Explaining why species diversity indices performed so poorly was the main purpose of this study. To do this, attention was directed towards 3 of the criteria (criteria b, c, and $d_{i}$ Table 1) that proved to be the most serious impediments to using species diversity indices.

Criterion b in Table 1 requires a good state indicator to be 'sensitive to a manageable human activity'. In the northern North Sea, analysis of Scottish August groundfish survey (SAGFS) data revealed steeper declines in groundfish species diversity in areas where fishing activity levels were highest (Greenstreet \& Hall 1996, Greenstreet et al. 1999, Greenstreet \& Rogers 2006), suggesting that species diversity indices were

Table 1. Traffic light system showing results of the application of the ICES criteria for a 'good state indicator' to species diversity indices (after ICES 2001). Green indicates no appreciable concerns; amber indicates some concerns; red indicates serious concerns

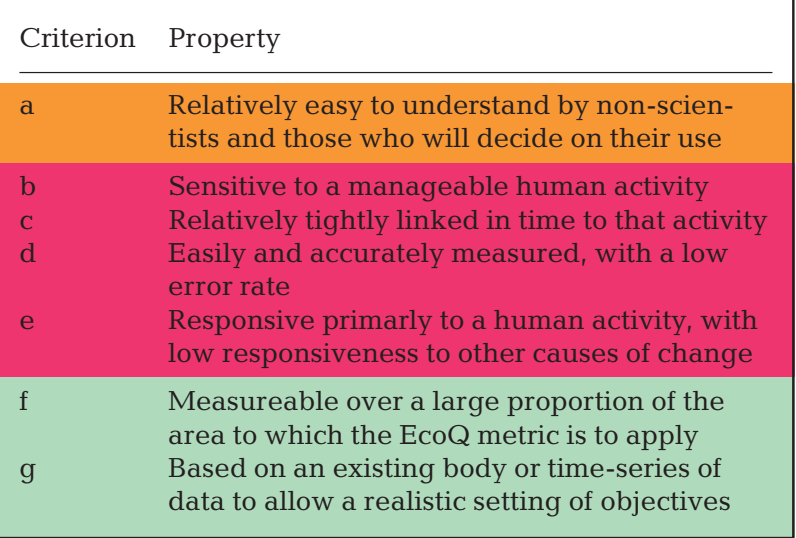

sensitive to fishing activity. However, other studies revealed no, or even positive, trends in species diversity, depending on the data set analysed (e.g. Rogers \& Ellis 2000, Piet \& Jennings 2005). This inconsistency led ICES (2001) to conclude that diversity indices were not particularly sensitive to fisheries-related impacts on the marine ecosystem (see also Chadwick \& Canton 1984, Robinson \& Sandgren 1984). Most diversity indices are sample-size dependent (Magurran 1988, Colwell et al. 2004). Frequently, problems have arisen through failure to appreciate the influence of sampling effort on index performance. If sampling effort requirements are not assessed a priori, the application of diversity indices to samples of inadequate size leads to insensitive metrics that fail to detect real differences in diversity (Soetaert \& Heip 1990, Boulinier et al. 1998).

The problem is exemplified by island biogeography theory, wherein species richness increases as a (Arrhenius) power function of the area sampled:

$$
S=\mathrm{c} A^{\mathrm{z}}
$$

where $S$ is the species richness count, $A$ the area sampled, and $\mathrm{c}$ and $\mathrm{z}$ are constants (MacArthur \& Wilson 1967, Rosenzweig 1995).

This implies that local $(\alpha)$ species richness (Hill's [1973] index $\mathrm{N}_{0}$ ) cannot be determined empirically without sampling the entire habitat area. Instead, by sequentially aggregating samples and tracking both the total aggregated species richness and the total aggregated area sampled, the species-area relationship (SAR) can be parameterised and used to model species richness in the area in question (e.g. Palmer 1988, 1990, Colwell \& Coddington 1994, Keating et al. 1998, Gotelli \& Colwell 2001, Storch et al. 2003, Ugland et al. 2003, Fridley et al. 2005, O'Hara 2005, van Gemerden et al. 2005). Species diversity indices that take account of relative species abundance are similarly influenced by sampling effort. Hill's (1973) $\mathrm{N}_{1}$ and $\mathrm{N}_{2}$ are, respectively, mathematically defined as:

$$
\mathrm{N}_{1}=\mathrm{e}^{-\sum_{s=1}^{S} p_{s}^{*} \ln \left(p_{s}\right)} \text { and } \mathrm{N}_{2}=1 / \sum_{s=1}^{S} p_{s}{ }^{2}
$$

where $p_{s}$ is the proportion of the total number of individuals sampled contributed by each of the $S$ species recorded in the sample (Magurran 1988).

The inclusion of additional species with increasing sampling effort increases the number of $p_{s}$ values in each of the summation terms, thereby affecting both indices.

Piet \& Jennings (2005) computed their richness and diversity index values as the 'mean value per haul' in each year of the 2 groundfish survey time-series that they analysed. However, as illustrated above, species richness of the community will always be higher than 
the number of species in any single sample (e.g. Brose et al. 2003). Calculating the mean species richness per sample still only provides an estimate of the average species richness in the average area covered in each sample, and therefore remains a poor indicator of the actual species richness of the community (e.g. Colwell et al. 2004). Reporting species richness as richness per unit sampling effort is theoretically unsound because, as indicated by the SAR, species richness $(S)$ is proportional to $A^{\mathrm{z}}$, and not just to $A$ alone (Rosenzweig 1995). Since $\mathrm{z}$ is a parameter that is characteristic of each community sampled, in each case, it is a parameter that needs to be estimated.

Application of the traditional Arrhenius power function assumes that local species assemblages are simply sub-sets of the regional species pool (Cornell \& Lawton 1992, Angermeier \& Winston 1998, Cornell \& Karlson 1997, Findley \& Findley 2001). However, studies examining the role of regional and local processes in dictating local species richness have demonstrated a phenomenon termed 'saturation'. After an initial sharp rise as the first samples are aggregated, the species accumulation rate drops markedly compared with the everincreasing traditional Arrhenius power function (Findley \& Findley 2001, Cottenie et al. 2003, Heino et al. 2003, Kiflawi et al. 2003, Wright et al. 2003). This has led to debate over which function best fits the SAR. There may be a fundamental difference between localand regional-scale SARs; the latter may be best fitted by the Arrhenius power function, while the former are best fitted by the Gleason semi-log plot, $S=\mathrm{c}+\mathrm{z}(\log A)$ (Whittaker 1972, van der Maarel 1988, Stohlgren et al. 1995). At local spatial scales, extrapolation from a traditional Arrhenius power function SAR could overestimate species richness in specified areas, such as ICES $0.5^{\circ}$ latitude by $1^{\circ}$ longitude statistical rectangles (Fridley et al. 2005).

Neither the Gleason nor the Arrhenius model is asymptotic in nature; both imply that additional sampling will always reveal new species. Species saturation could suggest that an asymptotic model, such as the Michaelis-Menton equation, might be more suitable to estimate local $(\alpha)$ diversity (e.g. Soberón \& Llorente 1993, Denslow 1995, Keating \& Quinn 1998). However, asymptotic models are only appropriate when the local habitat is absolutely defined (e.g. a mountain slope, Denslow 1995) and sampling is exhaustive (Magurran 2004). ICES statistical rectangles are arbitrarily defined and cover an area of approximately $3640 \mathrm{~km}^{2}$. The average groundfish survey rarely includes more than 4 trawl samples per rectangle, each covering an area of $0.07 \mathrm{~km}^{2}$, so sampling is not exhaustive. Asymptotic models therefore do not provide appropriate SARs to estimate ICES rectanglescale species richness.
The sample aggregation method may also influence the resultant SAR. Several authors (e.g. Rosenzweig 1995, Fridley et al. 2005) have suggested that samples be nested (each new area sampled is contiguous with the area sampled in samples lower in the aggregation order). In randomised aggregation, samples adjacent in the aggregation order may be separated in space, increasing the probability that the new sample will include new habitats, and hence add new species more quickly. Nested aggregation, focusing on $\alpha$-diversity, produces shallower species accumulation curves (Palmer 1990, Rosenzweig 1995), while a randomised approach may more rapidly incorporate elements of $\beta$-diversity (Colwell et al. 2004). The type of aggregation could have an influence on which SAR best fits the data: nested aggregation may be better fitted by the Arrhenius power function, while the Gleason semi-log plot may provide a better fit to randomised aggregations.

An alternative approach is to estimate the sample size required to derive indices of species richness and species diversity that reflect actual rankings in species richness and diversity in sampled communities. This may not provide estimates of actual species richness and diversity, but should allow temporal or spatial trends to be detected. This approach was adopted in the SAGFS studies discussed above. Preliminary analysis revealed that $10 \mathrm{~h}$ of Aberdeen 48-foot otter trawl effort was necessary before the aggregated sample obtained produced reliable estimates of Hill's $\mathrm{N}_{0}$, $\mathrm{N}_{1}$ and $\mathrm{N}_{2}$ (Greenstreet \& Hall 1996, Greenstreet et al. 1999, Greenstreet \& Rogers 2006). Accounting for sample-size dependency in this way provided indices sensitive enough to detect long-term, fishing-related declines in demersal fish species richness and diversity in the northwestern North Sea.

This approach, however, also has drawbacks. Marine sampling is difficult and expensive, limiting the level of sampling effort that is feasible. The best supported North Sea groundfish surveys, the ICES first (Q1) and third quarter (Q3) International Bottom Trawl Survey (IBTS), rarely achieve more than 3 trawl samples per ICES rectangle surveyed per year. Addressing spatial questions will therefore require the aggregation of samples collected over several years; conversely, investigating temporal issues will require the aggregation of samples collected across several ICES rectangles (e.g. Greenstreet \& Rogers 2006). Most studies will be directed towards estimating $\alpha$-diversity; the diversity in a particular location (habitat, ICES rectangle, etc.) at a given point in time. Aggregation across space risks including new species as new habitats get included in the aggregated sample area, thus confounding $\alpha$-diversity with $\beta$-diversity (Whittaker 1972, Lande 1996, Kiflawi \& Spencer 2004). Similarly, 
temporal turnover of vagrant species may lead to overestimation of species richness when samples are aggregated over time (Hadley \& Maurer 2001, Adler \& Lauenroth 2003, Adler et al. 2005, White et al. 2006, Magurran 2007, Shurin 2007). Both processes would therefore tend to inflate estimates of $\alpha$-species richness.

The lack of a consistent approach to estimating species diversity and species richness from groundfish species abundance data has produced inconsistent results. In the past, studies that took account of sample size dependency showed significant trends and demonstrated fishing effects, while studies that ignored sample size dependency produced results that were difficult to interpret. This inconsistency led ICES (2001) to conclude that metrics of species diversity and richness were either insensitive to a manageable human activity, or not tightly linked to the activity, illustrating that the use of diversity indices is not straightforward. Depending on how they are determined, indices of species richness and species diversity may not be easily and accurately measured. In a more recent treatise on the characteristics desirable in a state indicator, the capacity to convey information on aspects of the ecosystem that are of societal concern was assigned high priority (Rice \& Rochet 2005). Conserving and restoring biodiversity remain key principal policy drivers underlying the implementation of an EAM, which underlines the need for operational biodiversity state indicators. Addressing the problems identified by the application of the ICES criteria to biodiversity metrics is therefore an urgent priority for marine scientists.

A systematic approach to applying species diversity and richness metrics to groundfish survey data should rectify many of these problems, enabling such metrics to perform the role of state indicators and allowing the conservation and restoration of biodiversity to be addressed directly. Therefore, this study examines the sample size dependency of Hill's (1973) indices of species richness and diversity $\left(\mathrm{N}_{0}, \mathrm{~N}_{1}\right.$ and $\left.\mathrm{N}_{2}\right)$ in order to establish a standard procedure for their use. To demonstrate such a procedure, the question of mapping groundfish species richness and diversity across the North Sea is addressed. First, spatial variation in species composition is examined to ensure that, when selecting samples for sequential aggregation to explore the effect of sampling effort on metric performance, samples are drawn from similar species assemblages. Six such sites are selected covering a wide geographic area and 3 different assemblages. Having established a suitable procedure to estimate species richness and diversity in each ICES rectangle, spatial variation in the 3 Hill's metrics is determined by aggregating the necessary number of samples closest to the centre point of all rectangles included in the survey. The extent to which this spatial aggregation results in confounding elements of $\beta$-diversity into each of the individual ICES rectangle estimates of $\alpha$-diversity is then explored, and the impact this has on qualitative assessment of the resulting diversity maps is examined.

\section{METHODS}

The Q3 IBTS survey effort is approximately evenly distributed over ICES statistical rectangles across the whole North Sea. Each rectangle is usually fished by ships belonging to 2 participating countries using a grande ouverture verticale (GOV) trawl, resulting in at least 2 hauls per rectangle in most rectangles in most years. Numbers at length of all species caught are determined, and information on location, distance towed, and area swept by the gear is noted. Following previous practice (e.g. Greenstreet \& Hall 1996, Greenstreet et al. 1999), only data for species considered to be members of the 'demersal fish community' were analysed. Prior to 1998, not all participating countries used the same trawl gear, and tow durations varied. After 1998 all participating countries used the GOV trawl gear and tow duration was standardised to 30 min across the entire survey. Therefore, only data covering the period 1998 to 2004 were analysed. This produced the most consistent data set in terms of sampling procedure on which to base analyses of species diversity.

Data for a total of 2076 hauls were available. Despite fairly rigid protocols being laid down for the IBTS, these trawl samples varied markedly in terms of their swept area. Because of the sensitivity of diversity metrics to variation in sampling effort, 'valid' trawl samples were defined on the basis of swept area (Fraser et al. 2008), and only trawl samples conforming to this standard were analysed. This process resulted in approximately $8 \%$ of the IBTS trawl samples being excluded, leaving 1909 trawl samples with swept areas ranging from 51473 to $80835 \mathrm{~m}^{2}$ available for analysis.

Similarity in the species composition of the demersal fish community sampled in different ICES rectangles was assessed using the Bray-Curtis similarity index. Data for all trawl samples in each ICES rectangle were combined to provide a single species abundance 'sample'. Abundance data were root-root transformed to down-weight the effects of the more abundant species. Similarity between all pairs of ICES rectangles was determined. The resulting similarity matrix was subjected to hierarchical group-average cluster analysis to identify groups of ICES rectangles with demersal fish communities of similar species composition. These 
analyses were performed using the PRIMER software (Clarke \& Warwick 2001). Six ICES rectangles were chosen for detailed analysis of the influence of sampling effort on the performance of 3 species diversity indices. Criteria for selection were:

- the focal rectangles should be widely dispersed across the North Sea

- the focal rectangles should belong to at least 3 different species composition groups

- the number of trawls in the focal rectangles should be relatively high

- all rectangles adjacent to the focal rectangles should belong to the same species composition group.

There are 2 different aspects to species diversity: the actual number of species included in any particular sample, and the evenness of the distribution of individuals between all species encountered. Three metrics commonly used in analyses of groundfish survey data were applied (e.g. Greenstreet \& Hall 1996, Greenstreet et al. 1999, Piet \& Jennings 2005), each differing in the extent to which they are influenced by these aspects of species diversity (Southwood 1978). Hill's $\mathrm{N}_{0}$ is simply the count of all species (species richness) encountered in a sample, a metric strongly influenced by sampling effort variation. Two indices of species diversity (Hill's $\mathrm{N}_{1}$ and $\mathrm{N}_{2}$, the exponential of the Shannon-Weiner index and the reciprocal of Simpson's index, respectively) were also applied. The mathematical notation for both $\mathrm{N}_{1}$ and $\mathrm{N}_{2}$ is provided in Eq. (2). $\mathrm{N}_{1}$ is more sensitive to variation in the number of species recorded in a sample, whereas $\mathrm{N}_{2}$ is more sensitive to variation in the evenness of the distribution of individuals between species. All diversity metrics were determined using PRIMER (Clarke \& Warwick 2001).

At least 91 trawl samples (across all 7 years) were available for analysis in each of the 6 focal rectangles and their immediate neighbours. To apply the randomised aggregation method, 90 samples were selected at random (without replacement) from the available sample pool and sequentially aggregated. After the addition of each new sample, the total area swept by all aggregated samples was determined and the value of each of the 3 metrics calculated on the combined species abundance data. The order in which samples are aggregated affects the shape of the SAR, depending on whether the first sample in the accumulation order happens to be relatively species rich or species poor, compared with the remaining samples (Palmer 1990). To counter this, the sequential sample aggregation process was repeated 10 times, so that the order of aggregation was also randomised. Arrhenius power and Gleason semi-log functions were fitted to the data for all 10 randomisations. A true nested aggregation could not be carried out, because the IBTS trawl samples were not adjacent to each other in space. Such sampling has never been a survey requirement. However, as an approximation to this approach, 90 samples were aggregated in order of their distance from the centre-point of each of the 6 focal rectangles. Only one aggregation order fitted this criterion, so no replication was possible. Again, both the Arrhenius power and Gleason semi-log functions were fitted to the resulting accumulation curves.

As samples were aggregated to estimate ICES rectangle-scale index values for each of Hill's metrics, the actual extent of the area from which these samples were obtained also increased. Variation in the area from which the samples were collected was measured using a metric termed the 'search radius'. This was defined as the distance from the sample focal point (e.g. the centre position of an ICES rectangle) and the location of the most distant sample in the sample aggregation.

\section{RESULTS}

Cluster analysis of the ICES rectangle species abundance data revealed distinct groups of rectangles with similar species composition. When these clusters were mapped, clear spatial organisation was apparent (Fig. 1). On the basis of the data shown in Fig. 1 and the criteria given above, 6 ICES rectangles ('assemblages') were selected for investigation of the effect of sampling effort on species diversity index performance.

\section{Randomised aggregations}

In 5 of the 6 assemblages (the exception being Red2), the $\mathrm{R}^{2}$ values obtained (Table 2 ) suggested that species richness (Hill's $\mathrm{N}_{0}$ ) was best fitted by the Gleason semilog function, rather than by the Arrhenius power function (Fig. 2). Residuals to the Arrhenius power function showed a significant negative departure from the expected distribution at high sample aggregation levels (large $A$ ) in 4 (Red1, Green1, Green2 and Pink1) of the 6 rectangles (Fig. 2). Consequently, estimates of ICES statistical rectangle-scale $\left(3642 \mathrm{~km}^{2}\right.$ in the central North Sea) species richness based on extrapolation of the fitted Arrhenius power functions were unrealistically high (Table 2). The total North Sea fish species inventory, including pelagic species excluded from this analysis, has been estimated at around 224 species (Yang 1982). Extrapolation of the Gleason semi-log functions provided more reasonable estimates of rectangle-scale species richness (Table 2). However, residuals to the Gleason semi-log function showed a significant positive departure from the expected distribution at high sample aggregation levels in the other 

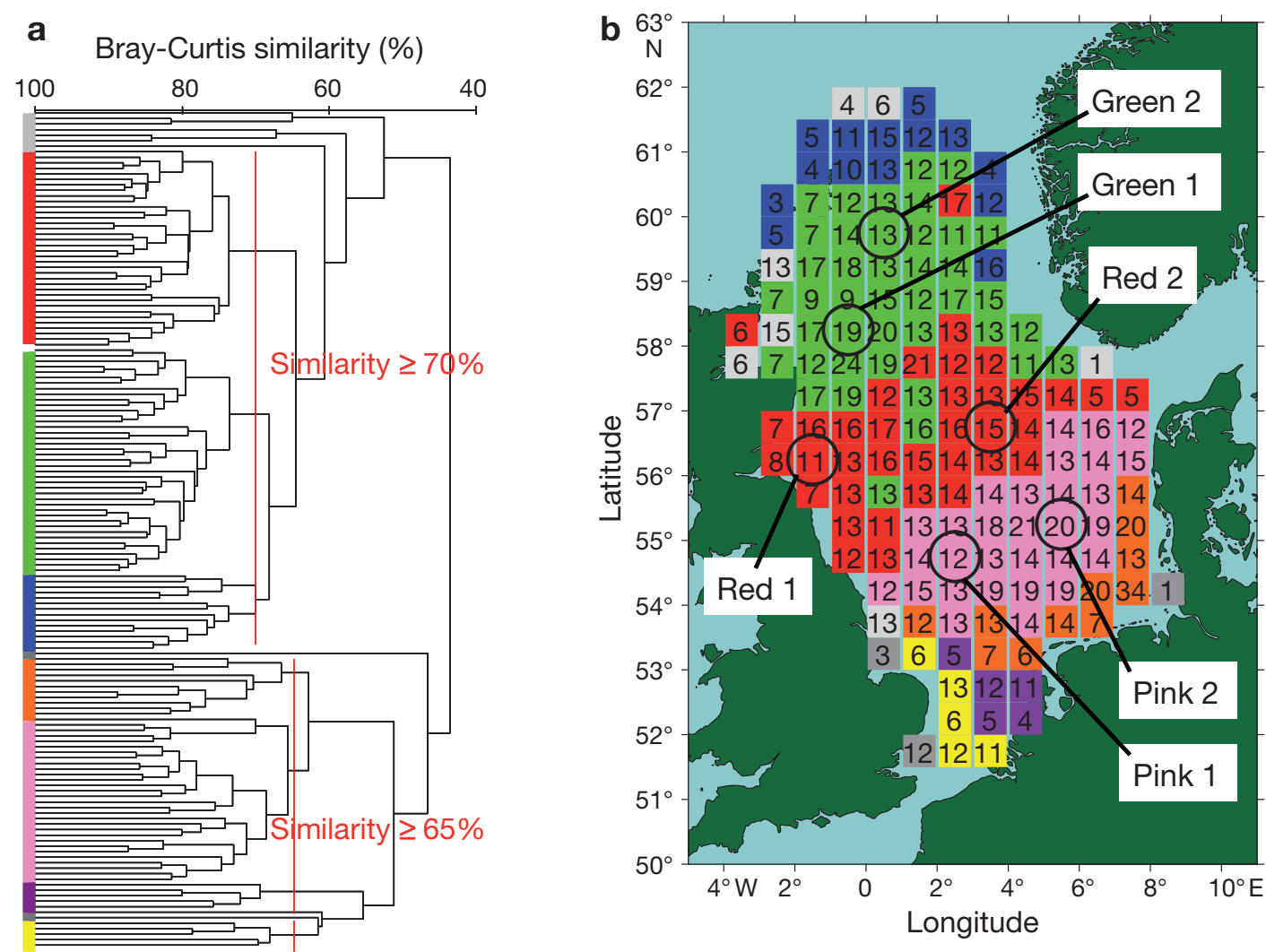

Fig. 1. (a) Results of hierarchical group-averaging cluster analysis of the Bray-Curtis similarity matrix constructed for the International Bottom Trawl Survey (IBTS) grande ouverture verticale (GOV) data set. Clusters of ICES rectangles grouped at similarity levels of 65 and $70 \%$ are colour coded. (b) Chart of spatial distribution of groups from (a). The chart indicates the number of GOV trawl samples available for analysis in each ICES rectangle over the full period 1998 to 2004. The 6 focal rectangles (assemblages) selected for 'sample-size' analyses are annotated

2 assemblages, Red2 and Pink2 (Fig. 2), suggesting that, in these cases, the Gleason semi-log function might under-estimate ICES rectangle-scale species richness. In summary, 5 of the assemblages (Red1, Green1, Green2, Pink1 and Pink2) were better fitted by the Gleason semi-log function, but with Pink2, showing significant positive deviations from the fit at high sample aggregation levels, and 1 assemblage, Red2, was best fitted by the Arrhenius power function.

The Arrhenius and Gleason functions produced a similar, but not identical, ranking of the 6 assemblages in terms of their ICES rectangle-scale species richness (Table 2). The Arrhenius power function ranked the assemblages Pink1 > Green1 > Red1 > Green2 > Pink2 $>$ Red2, while the Gleason semi-log function interchanged the first and second, and third and fourth rectangles to rank the assemblages Green1 $>$ Pink1 > Green2 > Red1 > Pink2 > Red2. However, 95\% confidence limits (CLs) around the ICES rectangle-scale estimates of species richness of both the interchanged assemblage pairs overlapped, regardless of the SAR applied to the data (Table 2). Neither of the SARs could therefore provide a definitive ranking order for these 2 assemblage pairs. Given that the Gleason semi-log function provided the best fit to the data from the 4 topranked assemblages, the latter ranking is probably the most reliable. Even though the Gleason semi-log function probably underestimated species richness in the 2 lowest-ranked assemblages, these same 2 assemblages were also ranked lowest, and in the same order, by the Arrhenius power function.

More critically, the assemblage rankings were not established until both SARs had been extrapolated to areas greater than $40 \mathrm{~km}^{2}$. At aggregation levels of 90 trawl samples, the total area sampled was approximately $7 \mathrm{~km}^{2}$ (Fig. 3), suggesting that the sampling required to rank fish communities using empirical estimates of ICES rectangle-scale groundfish species richness (i.e. based simply on aggregated sample species counts) would be too onerous and well beyond current, or likely, levels of groundfish survey activity. However, the situation is not as stark as this initial assessment suggests. Deciding relative species richness rankings between the Red1 and Green2 and between the Pink1 and Green 1 assemblages posed the greatest difficulty when using the Arrhenius power function (Fig. 3). 
Table 2. Parameter values and ICES rectangle scale Hill's $\mathrm{N}_{0}$, species richness values obtained by the application of the Arrhenius power $\left(\mathrm{N}_{0}=\mathrm{c} A^{\mathrm{z}}\right)$ and Gleason semi-log $\left(\mathrm{N}_{0}=\mathrm{C}+\mathrm{z} \log A\right)$ functions to species-area accumulation data derived from the randomised and nested sequential aggregation of 90 Q3 IBTS trawl samples in each of 6 focal ICES rectangles and their immediate neighbouring rectangles. 95\% confidence limit (CL) ranges around each estimate of ICES rectangle-scale species richness are also indicated

\begin{tabular}{|c|c|c|c|c|c|}
\hline Assemblage & C & $\mathrm{z}$ & $\mathrm{R}^{2}$ & $\mathrm{~N}_{0}$ & $95 \%$ CL range \\
\hline \multicolumn{6}{|c|}{ Arrhenius power } \\
\hline \multicolumn{6}{|c|}{ Randomised } \\
\hline Red1 & 0.5226 & 0.2744 & 0.926 & 220 & $205-235$ \\
\hline Red2 & 0.6748 & 0.2353 & 0.891 & 120 & $112-129$ \\
\hline Green1 & 0.6466 & 0.2674 & 0.914 & 233 & $217-250$ \\
\hline Green2 & 0.8483 & 0.2467 & 0.908 & 194 & $181-207$ \\
\hline Pink1 & 0.3697 & 0.3004 & 0.857 & 275 & $247-307$ \\
\hline Pink2 & 0.5619 & 0.2646 & 0.871 & 190 & $174-208$ \\
\hline \multicolumn{6}{|l|}{ Nested } \\
\hline Red1 & 0.2493 & 0.3179 & 0.968 & 273 & $230-324$ \\
\hline Red2 & 0.3492 & 0.2841 & 0.913 & 182 & $140-235$ \\
\hline Green1 & 0.2917 & 0.3166 & 0.963 & 310 & $259-372$ \\
\hline Green2 & 0.4356 & 0.2875 & 0.960 & 244 & $205-290$ \\
\hline Pink1 & 0.0226 & 0.4824 & 0.956 & 926 & $680-1260$ \\
\hline Pink2 & 0.1994 & 0.3241 & 0.909 & 250 & $185-339$ \\
\hline \multicolumn{6}{|c|}{ Gleason semi-log } \\
\hline \multicolumn{6}{|c|}{ Randomised } \\
\hline Red1 & -60.8624 & 14.206 & 0.945 & 75 & $73-77$ \\
\hline Red2 & -39.3651 & 9.578 & 0.872 & 52 & $50-54$ \\
\hline Green1 & -65.3583 & 15.455 & 0.954 & 82 & $81-84$ \\
\hline Green2 & -58.1251 & 14.154 & 0.933 & 77 & $75-79$ \\
\hline Pink1 & -66.7891 & 15.297 & 0.879 & 79 & $77-82$ \\
\hline Pink2 & -54.1805 & 12.838 & 0.879 & 69 & $66-71$ \\
\hline \multicolumn{6}{|l|}{ Nested } \\
\hline Red1 & -66.1030 & 14.600 & 0.946 & 73 & $69-78$ \\
\hline Red2 & -47.0834 & 10.966 & 0.945 & 58 & $54-62$ \\
\hline Green1 & -74.8645 & 16.602 & 0.987 & 84 & $81-87$ \\
\hline Green2 & -68.8151 & 15.543 & 0.945 & 80 & $75-85$ \\
\hline Pink1 & -98.2670 & 19.795 & 0.913 & 91 & $83-99$ \\
\hline Pink2 & -68.9492 & 14.650 & 0.825 & 71 & $62-80$ \\
\hline
\end{tabular}

Similarly, defining the ranking order of the Pink1 and Green2 assemblages was hardest when using the Gleason semi-log function (Fig. 3). For clarity, 95\% CLs were not shown in Fig. 3, but reference to Table 2 reveals that the $95 \%$ CLs around the species richness estimates of each assemblage within these assemblage pairs overlap. Within each pair, the assemblage ranking order could not therefore be conclusively defined, and if this is the case, Fig. 3 suggests that extrapolation of the SARs to an area of $7 \mathrm{~km}^{2}$ was sufficient to provide relative species richness rankings. Estimates of species richness capable of ranking the species richness of different ICES rectangle groundfish assemblages might therefore be empirically derived from aggregated collections of 90 half-hour GOV trawl samples.

The sample aggregation-species diversity plots for the 2 species diversity indices, Hill's $N_{1}$ and $N_{2}$, revealed horizontal, funnel-shaped forms that differed markedly from the species richness (Hill's $\mathrm{N}_{0}$ ) 'data clouds' (Fig. 2). This is because $\mathrm{N}_{1}$ and $\mathrm{N}_{2}$ take account of both aspects of diversity, species richness and species evenness. With species richness, it is possible that the first sample in the accumulation order might be particularly species rich or particularly species poor, thereby causing the observed spread of data at the left of the data clouds (Fig. 2). However, it is also inevitable that, as the combined area sampled increases, new species will be added to the aggregated total, no matter how high the initial start point. Stochastic variation in the species richness of the first samples aggregated also affects $N_{1}$ and $N_{2}$ in a similar fashion, causing the generally positive convex shape of the data clouds in many of the plots (Fig. 2). However, the degree of evenness also varies in a stochastic manner, so that the first samples in an aggregation order might be characterized by relatively low levels of dominance (unusually low abundance of normally dominant species, or higher-than-usual abundance of some less common species), resulting in unusually high $\mathrm{N}_{1}$ and $\mathrm{N}_{2}$ values. Further accumulation of additional samples characterized by more normal levels of dominance then causes aggregated $\mathrm{N}_{1}$ and $\mathrm{N}_{2}$ values to fall. This gives rise to the characteristic funnel-shaped data clouds prevalent in Fig. 2. Since neither of the SARs can be consistently fitted to either of the diversity indices, a similar statistical model-fitting approach to estimating species diversity at the ICES rectangle spatial scale was not possible. However, once the total aggregated area sampled was sufficiently large, the data tended to stabilize around mean index values. Therefore, the mean index value, calculated across all 10 randomised aggregations of 90 samples, probably provides the most reliable estimate of species diversity at the ICES rectangle scale for each of the 6 assemblages (Table 3 ).

\section{Nested aggregations}

Arrhenius power functions provided marginally higher $\mathrm{R}^{2}$ values for 4 (Red1, Green2, Pink1 and Pink2) 


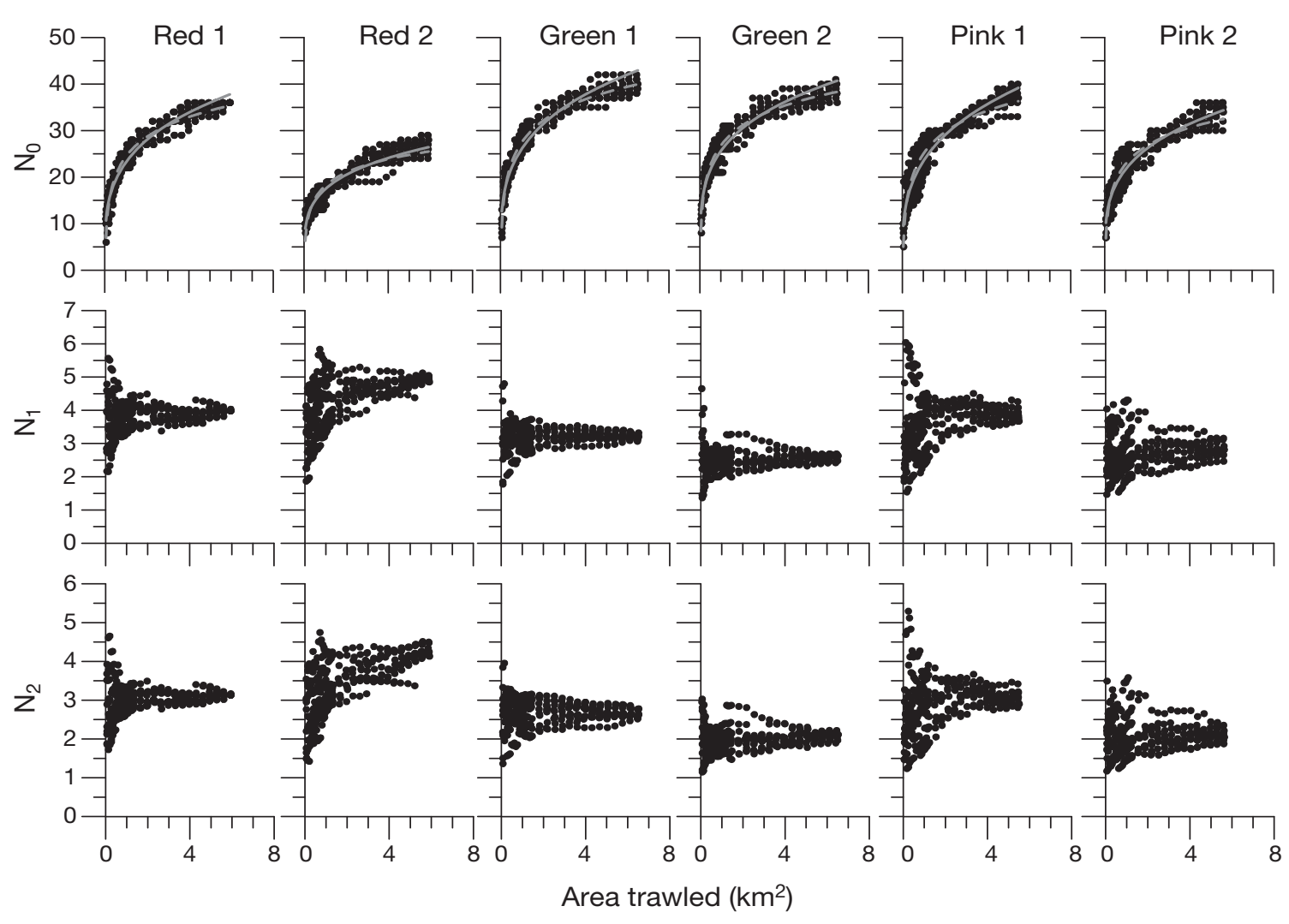

Fig. 2. Effect of increasing area sampled on Hill's $\mathrm{N}_{0}$ (species richness), $\mathrm{N}_{1}$, and $\mathrm{N}_{2}$ (species diversity) index values for each of the 6 assemblages, using a randomised sequential aggregation of 90 samples. Data for 10 separate randomised aggregations are plotted. For $\mathrm{N}_{0}$, solid grey lines show Arrhenius power function fits to the data; dashed grey lines show Gleason semi-log fits to the data
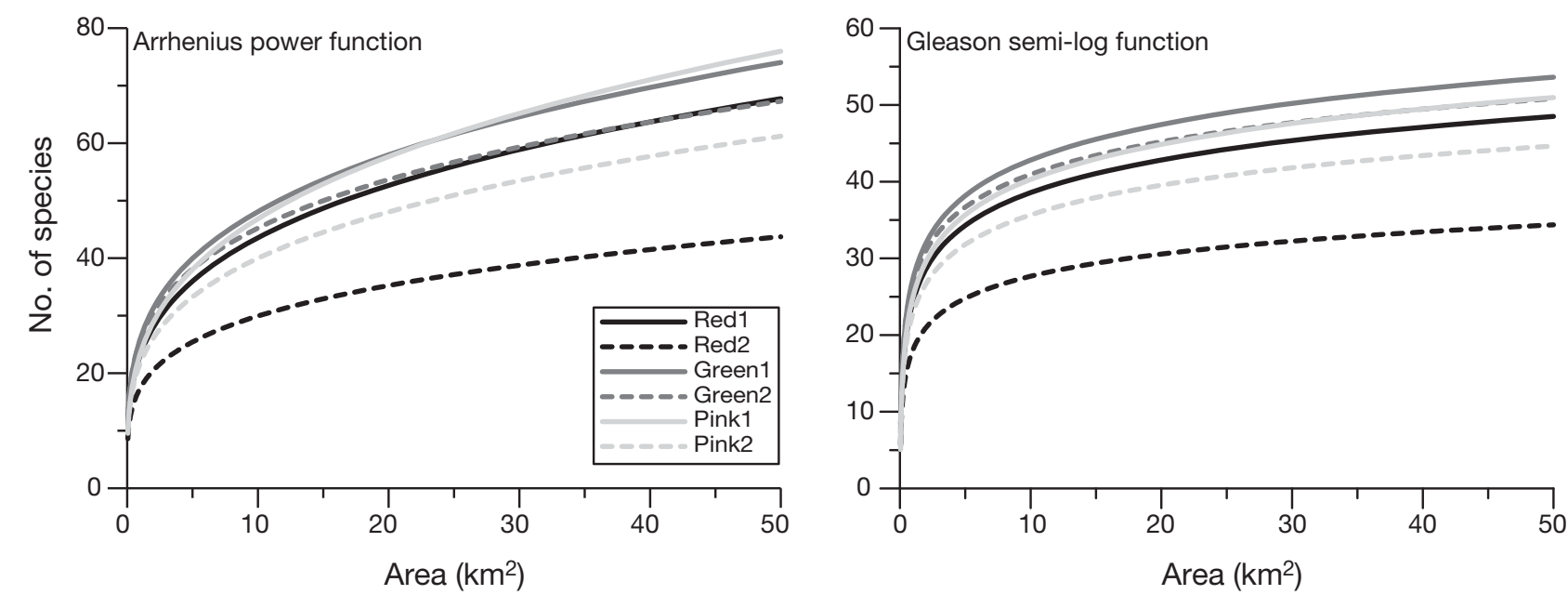

Fig. 3. Extrapolation of the Arrhenius power and Gleason semi-log functions up to $50 \mathrm{~km}^{2}$, illustrating overlaps in each type of species-area relationship (SAR) fitted to the 6 assemblages. Final rankings are not established until extrapolation to areas greater than $40 \mathrm{~km}^{2}$

of the 6 assemblages species richness plots (Fig. 4), but in all cases extrapolation to the area of an ICES rectangle again resulted in unrealistically high estimates of species richness (Table 2). Gleason semi-log functions may not have fitted the data quite so well, but the differences were small, and extrapolation to the ICES rectangle scale resulted in more reasonable estimates of species richness (Table 2). The Arrhenius function ranked the 6 assemblages Pink1 > Green1 > Red1 > Pink2 > Green2 > Red2, while the Gleason function 
Table 3. Average Hill's $\mathrm{N}_{0}$ (species richness), $\mathrm{N}_{1}$, and $\mathrm{N}_{2}$ (species diversity) index values, calculated across 10 randomised aggregations of 90 trawl samples for 6 North Sea groundfish assemblages

\begin{tabular}{|lccc|}
\hline Assemblage & $\mathrm{N}_{0}$ & $\mathrm{~N}_{1}$ & $\mathrm{~N}_{2}$ \\
\hline Red1 & 36 & 3.99 & 3.14 \\
Red2 & 27 & 4.94 & 4.26 \\
Green1 & 40 & 3.19 & 2.63 \\
Green2 & 39 & 2.59 & 2.07 \\
Pink1 & 37 & 3.89 & 3.07 \\
Pink2 & 34 & 2.83 & 2.12 \\
\hline
\end{tabular}

ranked them Pink1 > Green1 > Green2 > Red1 > Pink2 > Red2, elevating the fifth ranked assemblage into third place. In both cases, the $95 \%$ CLs around the ICES rectangle-scale species richness estimates for the assemblages ranked 3, 4 and 5 overlapped, so neither SAR could conclusively rank these 3 assemblages. For each SAR, the aggregation method had little effect on the assemblage rankings. Compared with the randomised aggregation, nested aggregations transposed the fourth- and fifth-ranked assemblages using the Arrhenius function, whilst the first and second assem- blages were transposed when the Gleason function was used. In both cases, the $95 \%$ CLs around the ICES rectangle-scale species richness estimates for the assemblages concerned again overlapped. A Spearman rank correlation matrix, comparing the 4 sets of species richness estimates, confirmed the similarity in ranking order achieved by all 4 methods (Table 4), but no 2 ranking orders were identical.

Nested aggregation plots for Hill's $\mathrm{N}_{1}$ and $\mathrm{N}_{2}$ species diversity indices revealed a variety of forms (Fig. 4), demonstrating the interplay between species richness and species evenness in influencing index behaviour with increasing sampling effort. Index values stabilised to some extent, once the aggregated sample area exceeded 1 to $2 \mathrm{~km}^{2}$. However, compared with the randomised aggregation plots (Fig. 2), even in the final stages of aggregation, clear positive or negative trends in both indices were still apparent for several of the assemblages, making it difficult to determine appropriate index values.

The nested aggregation plots for all 3 of Hill's indices were not smooth (Fig. 4), suggesting the influence of processes other than simply the effect of increasing the area sampled. Fig. 5 shows similar plots, but here the index values are plotted against search radius (the dis-

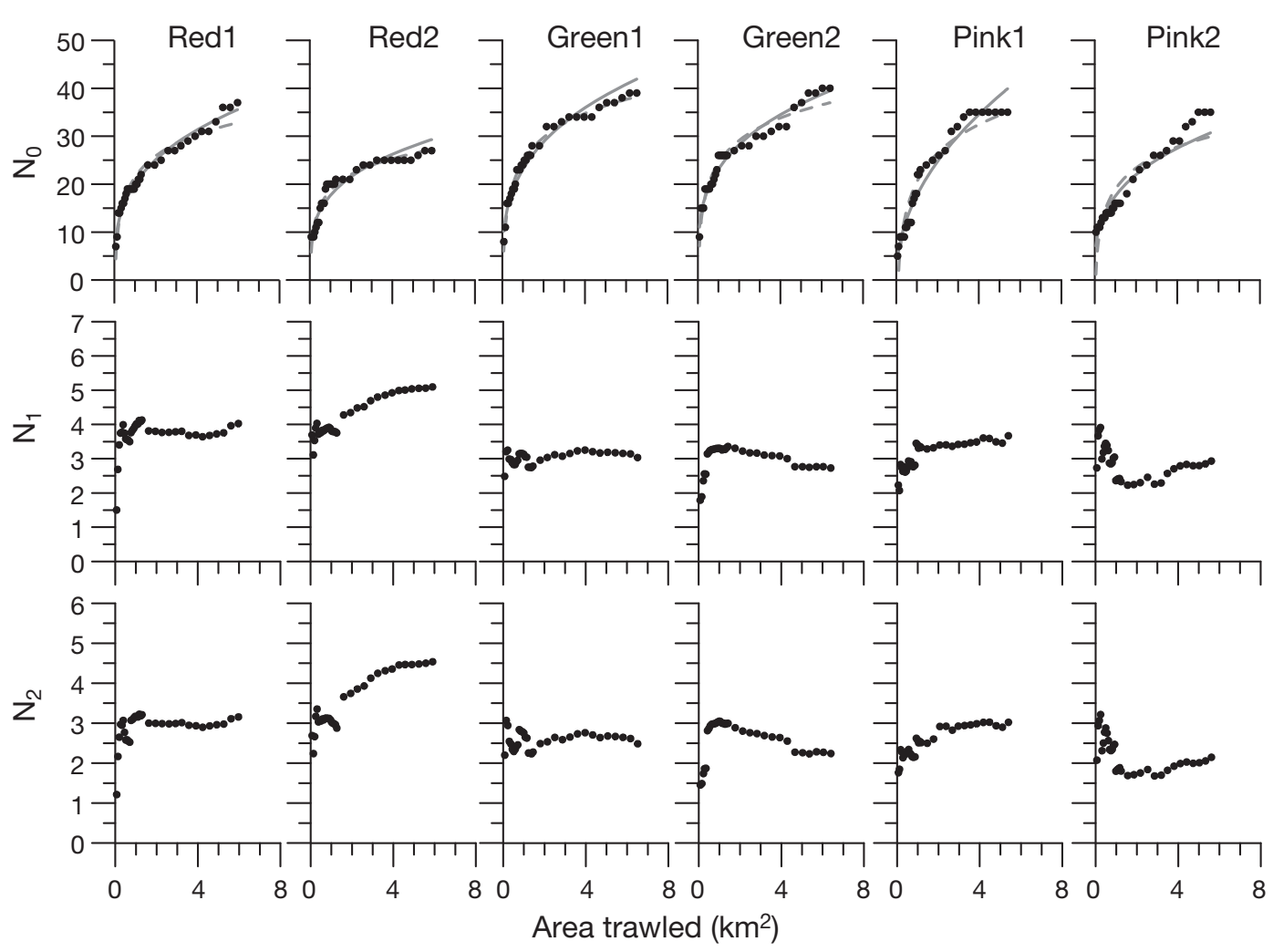

Fig. 4. Effect of increasing the area sampled $\left(\mathrm{km}^{2}\right)$ on Hill's $\mathrm{N}_{0}$ (species richness), $\mathrm{N}_{1}$, and $\mathrm{N}_{2}$ (species diversity) index values in each of the 6 assemblages, using a nested sequential aggregation of 90 samples. For $\mathrm{N}_{0}$, solid grey lines show Arrhenius power function fits to the data; dashed grey lines show Gleason semi-log fits to the data 
Table 4. Spearman correlation coefficients (upper right cells), comparing the ranking order of 6 groundfish assemblages in terms of the species richness determined by extrapolation of Arrhenius power or Gleason semi-log functions, fitted to randomised or nested aggregated sample data up to the spatial scale of the ICES rectangle. Significance levels are indicated (lower left cells; n.s.: $\mathrm{p}>0.05)$

\begin{tabular}{|llllcc|}
\hline \multirow{2}{*}{ Aggregation } & \multirow{2}{*}{ Function } & \multicolumn{2}{c}{ Randomised } & \multicolumn{2}{c|}{ Nested } \\
& & Arrhenius & Gleason & Arrhenius & Gleason \\
\hline \multirow{2}{*}{ Randomised } & Arrhenius & & 0.866 & 0.943 & 0.943 \\
\cline { 2 - 4 } Nested & Gleason & $\mathrm{p}<0.05$ & & 0.771 & 0.943 \\
& Arrhenius & $\mathrm{p}<0.01$ & $\mathrm{p}=$ n.s. & & 0.829 \\
& Gleason & $\mathrm{p}<0.01$ & $\mathrm{p}<0.01$ & $\mathrm{p}<0.05$ & \\
\hline
\end{tabular}

tance between each new sample in the aggregation and the centre of the ICES rectangle concerned). Fifthorder polynomial functions fitted to these data indicated multi-phasic species accumulation curves with marked increases in the species accumulation rate at search distances of around 40 to $50 \mathrm{~km}$. This was almost certainly associated with the incorporation of elements of $\beta$-diversity into the estimate of species richness as the region within the expanding search radius included new habitats with different species composition.

\section{Assessing sample size requirements for assemblage ranking}

For each of the 6 assemblages, the average index value across each of the 10 randomised aggregations of 90 trawl samples provided the best empirical estimates of each metric for each assemblage (Table 3). This ranked the 6 assemblages, in terms of species richness (Hill's $\mathrm{N}_{0}$ ), Green1 > Green2 > Pink1 > Red1 > Pink2 > Red2. Similar to the ranking derived from extrapolation of the randomised aggregation Gleason semi-log SARs to the ICES rectangle scale, just the second and third ranked assemblages were transposed. This confirms the point made above and illustrated in Fig. 3. Even after aggregating 90 trawl samples, the ranking of empirical estimates of species richness, based on aggregated sample species counts, did not exactly match the ranking obtained by extrapolating Gleason semi-log SARs to the ICES rectangle scale. Hill's $\mathrm{N}_{1}$ and $\mathrm{N}_{2}$ both ranked the 6 assemblages in identical order: Red2 > Red1 > Pink1 > Green1 > Pink2 > Green2.
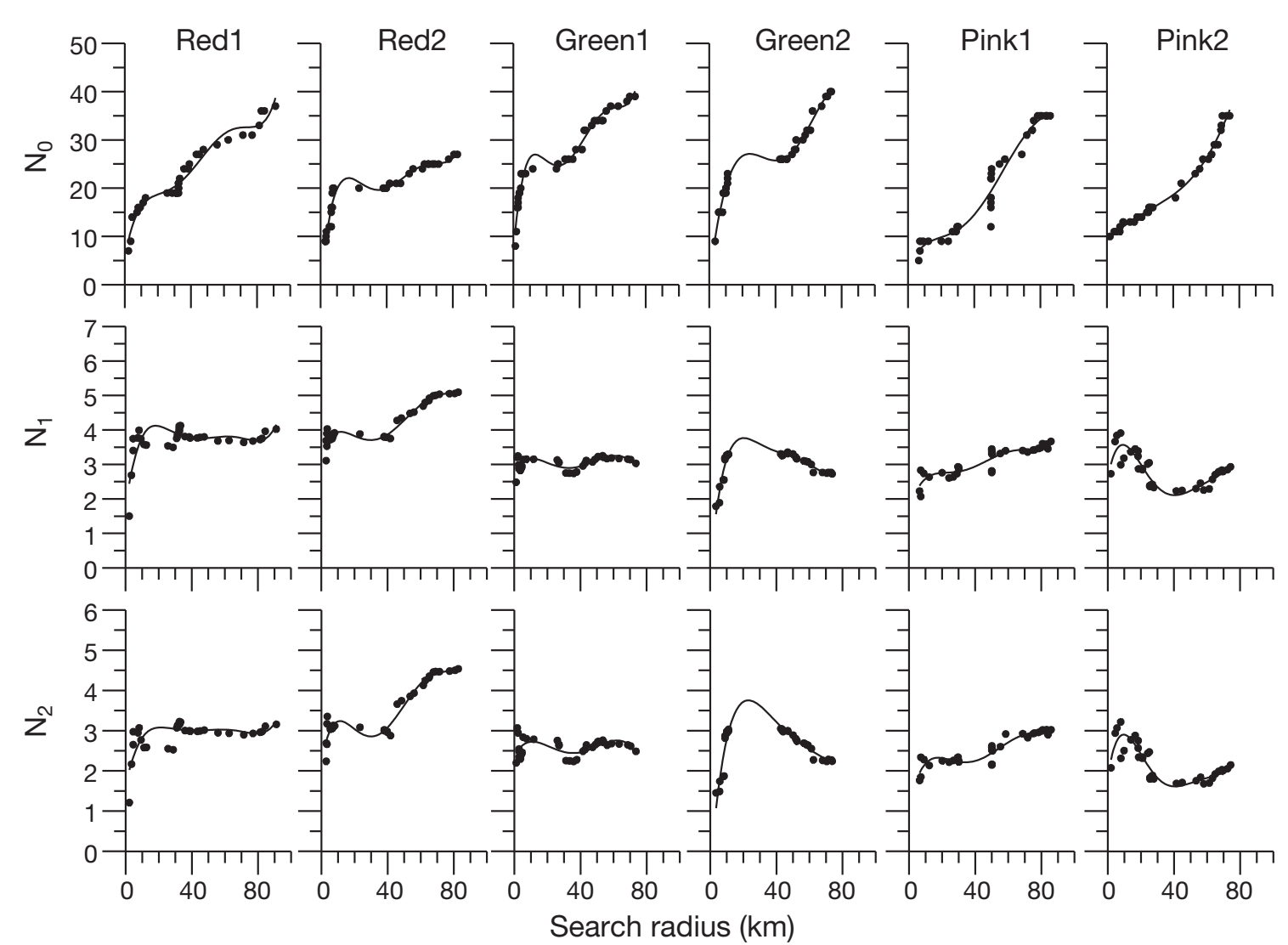

Fig. 5. Effect of increasing search radius $(\mathrm{km})$ on Hill's $\mathrm{N}_{0}$ (species richness), $\mathrm{N}_{1}$, and $\mathrm{N}_{2}$ (species diversity) index values in each of the 6 assemblages using a nested sequential aggregation of 90 samples. Fitted curves are assemblages fifth-order polynomials 
Next, the level of sample aggregation required in order to have a good chance of ranking the assemblages in the correct order was assessed using Pearson's correlation. Values determined for each metric at each aggregation level (as $y$ variables) were compared with the mean values obtained for each metric when 90 trawls samples were aggregated (as $x$ variables; i.e. Table 3). Correlation coefficients approaching 1 indicated good performance, while scores near zero indicated poor performance. Negative coefficients implied a reversal of the correct ranking order. Since 10 randomisations were carried out, means and standard deviations of the correlation coefficient at each aggregation level could be determined (Fig. 6). For each of the 3 metrics, aggregation of at least 20 trawl samples was required. By this point, mean Pearson's R was close to the curve asymptotes ( $>0.75$ in all cases), and the standard deviations around these mean values had declined by more than $66 \%$. This does not mean that estimates of species richness based on 20 GOV trawl samples indicate actual species richness in any given ICES rectangle. Rather, it suggests that measures of species richness based on 20 or more samples are sufficient to compare species richness between different locations or different times.

\section{Mapping species richness and species diversity}

Hill's $\mathrm{N}_{0}, \mathrm{~N}_{1}$ and $\mathrm{N}_{2}$ indices for each ICES statistical rectangle were derived from the aggregation of the 20 trawl samples closest to each rectangles' central point and maps of spatial variation of species richness and diversity were plotted (Fig. 7). Species composition of the North Sea groundfish community varied significantly across space; the greater the distance between 2 ICES rectangles, the more different the communities at each location were (Fig. 8). This confirmed the possibility that aggregating samples in space posed a real risk of confounding $\beta$-diversity with $\alpha$-diversity, leading to inflated estimates of the latter. Consequently, in mapping the 3 indices (Fig. 7), ICES rectangles requiring a search radius of $>95 \mathrm{~km}$ in order to aggregate 20 samples were excluded. Relationships between search radius and each metric were then examined to ensure that this precaution was sufficient to preclude the incorporation of $\beta$-diversity.

Since all metric values were based on identical sample size, there was no reason to anticipate that the metric values should be influenced by the search radius. However, this assumption was falsified with respect to Hill's $N_{0}$, the species richness index (Fig. 9). Below a search radius of $49 \mathrm{~km}, \mathrm{~N}_{0}$ was independent of search radius, but above this distance, $\mathrm{N}_{0}$ was significantly linearly related to search radius, suggesting increasing inclusion of $\beta$-diversity. For all rectangles where the search radius required to 'capture' 20 trawl samples exceeded $49 \mathrm{~km}$, this linear regression was used to estimate the $\beta$ diversity contribution $\left(\mathrm{N}_{0, \beta}\right)$ where $\mathrm{N}_{0, \beta}=$ $\hat{\mathrm{N}}_{0, \mathrm{SR}}=x-\hat{\mathrm{N}}_{0, \mathrm{SR}}=49 . \hat{\mathrm{N}}_{0, \mathrm{SR}}=x$ and $\hat{\mathrm{N}}_{0, \mathrm{SR}}=49$ are the estimates of $\mathrm{N}_{0}$ obtained from the regression equation at the observed search radius for each of the rectangles concerned and at a search radius of $49 \mathrm{~km}$, respectively. This estimated $\beta$-diversity contribution was then subtracted from actual observed estimates of $\mathrm{N}_{0}$ in each rectangle for which the search radius exceeded
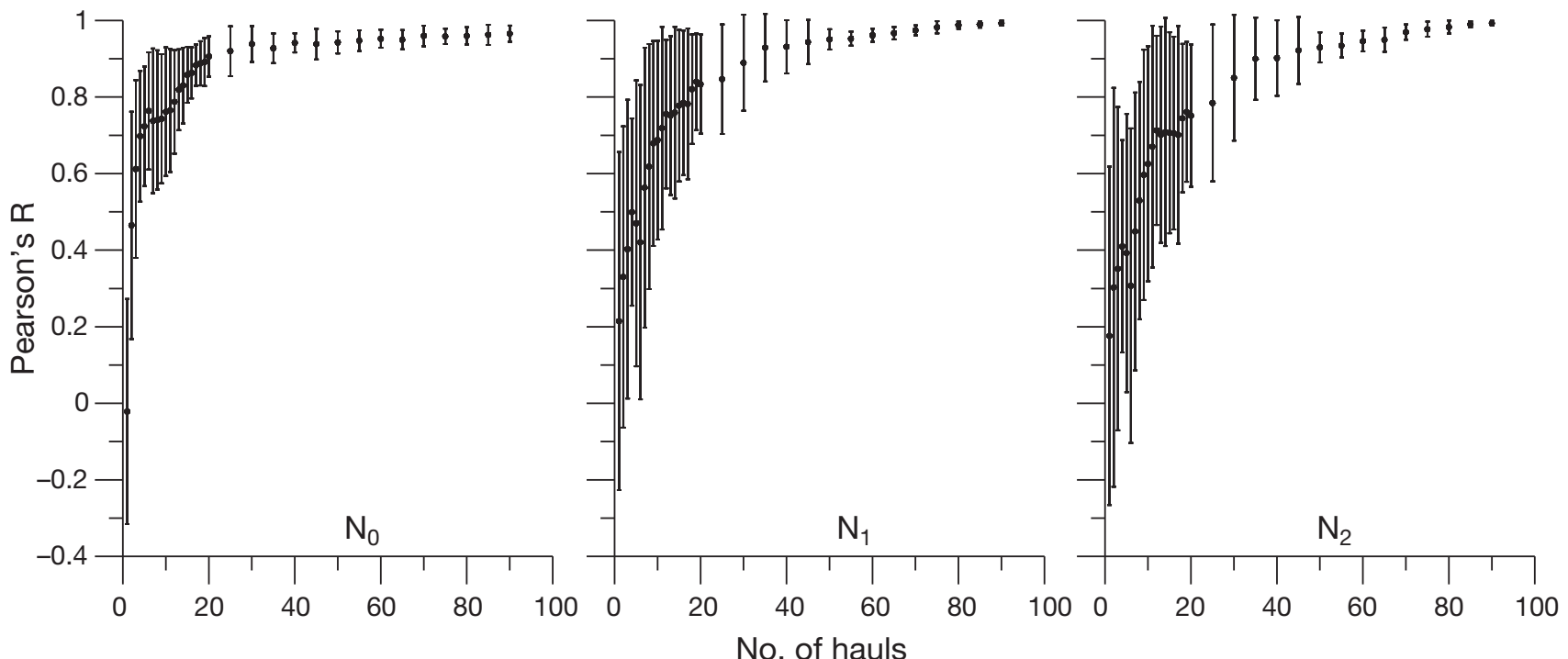

Fig. 6. Mean ( $\pm 1 \mathrm{SD}$ ) Pearson correlation scores for different sample aggregation levels of Hill's $\mathrm{N}_{0}, \mathrm{~N}_{1}$, and $\mathrm{N}_{2}$ diversity metrics 

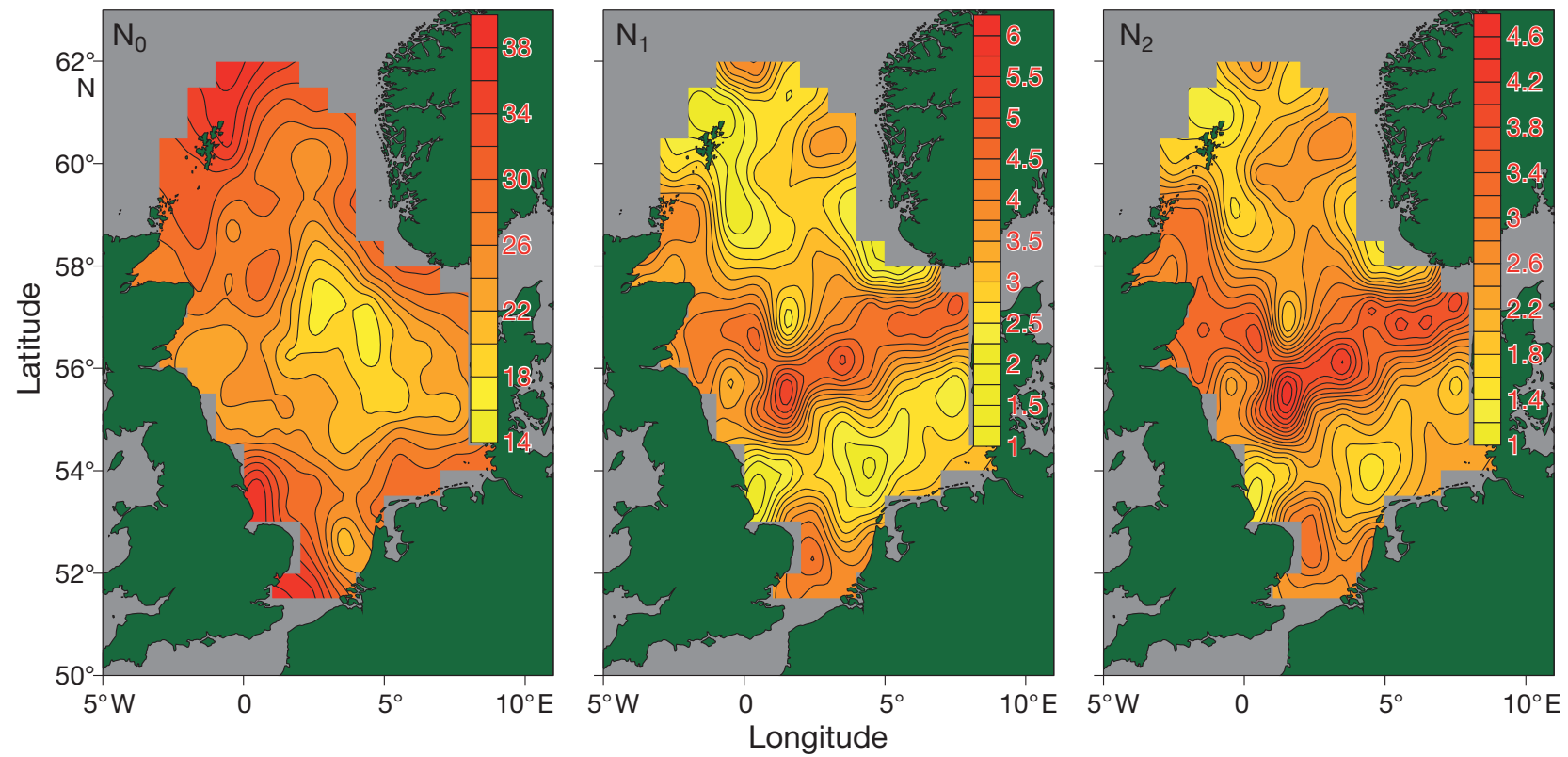

Fig. 7. Spatial variation in Hill's $\mathrm{N}_{0}, \mathrm{~N}_{1}$ and $\mathrm{N}_{2}$ across the North Sea, based on aggregation of the 20 Q3 IBTS trawls closest to the central point of each ICES statistical rectangle. Interpolation is by radial basis function in SURFER

$49 \mathrm{~km}$. Spatial variation in species richness $\left(\mathrm{N}_{0}\right)$ across the North Sea was then re-mapped (Fig. 10). Little difference was apparent between this revised map and the original map (Fig. 7), suggesting that the incorporation of elements of $\beta$-diversity in some instances had little effect on qualitative interpretation of spatial variation in $\alpha$-diversity across the North Sea.

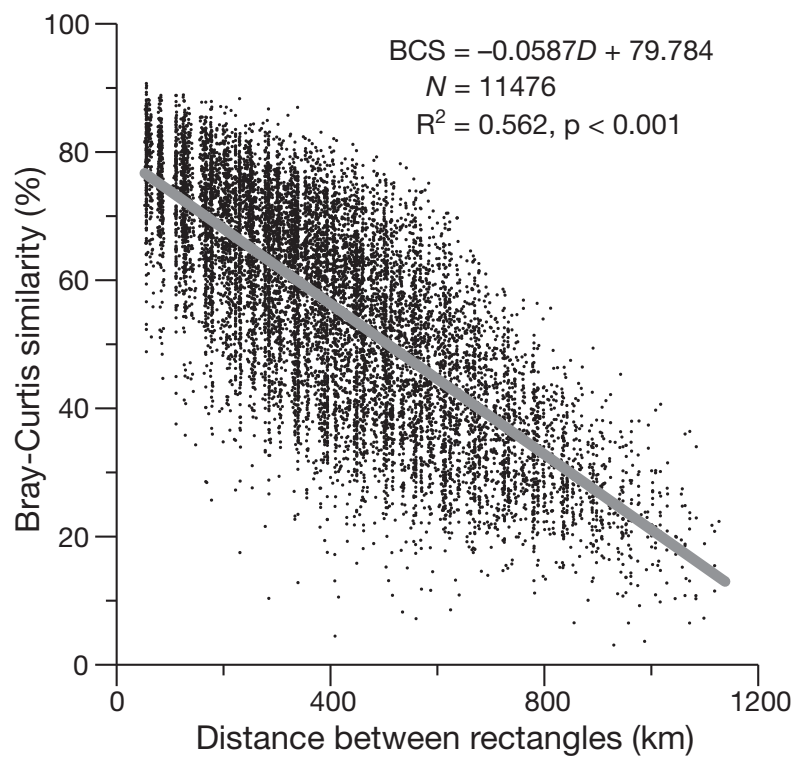

Fig. 8. Relationship between the Euclidean distance between pairs of ICES rectangles and the Bray-Curtis similarity (BCS) in species composition of the groundfish community present in each rectangle

\section{DISCUSSION}

The current EcoQO for fish communities in the North Sea concentrates on the restoration of community size structure because fish size metrics were believed to comply with the ICES criteria for good state indicators (ICES 2007). Indices of biodiversity, on the other hand, were considered to violate too many of these criteria to be of use within a management context. Conflicting and inconsistent results in studies undertaken in the North Sea implied that indices of species richness and species diversity were not sensitive to a manageable human activity, not responsive primarily to that human activity, not tightly linked in time to that activity, or not easily and accurately measured. Hill's $\mathrm{N}_{0}, \mathrm{~N}_{1}$ and $\mathrm{N}_{2}$, the indices of species richness and species diversity most commonly applied to North Sea groundfish survey data, are shown here to be strongly influenced by variation in sampling effort. When the influence of sampling effort has been taken into account by a priori assessing and then meeting sampling effort requirements, these indices were sensitive to drivers of change in a community (e.g. Greenstreet \& Rogers 2006). However, when the influence of sampling effort was ignored, results were less conclusive (e.g. Piet \& Jennings 2005). Failure to follow a standard methodology in applying Hill's diversity indices to groundfish survey data, rather than any failing in the indices themselves, may largely be responsible for giving the impression that these metrics are insensitive to drivers of change in the North Sea groundfish community. 

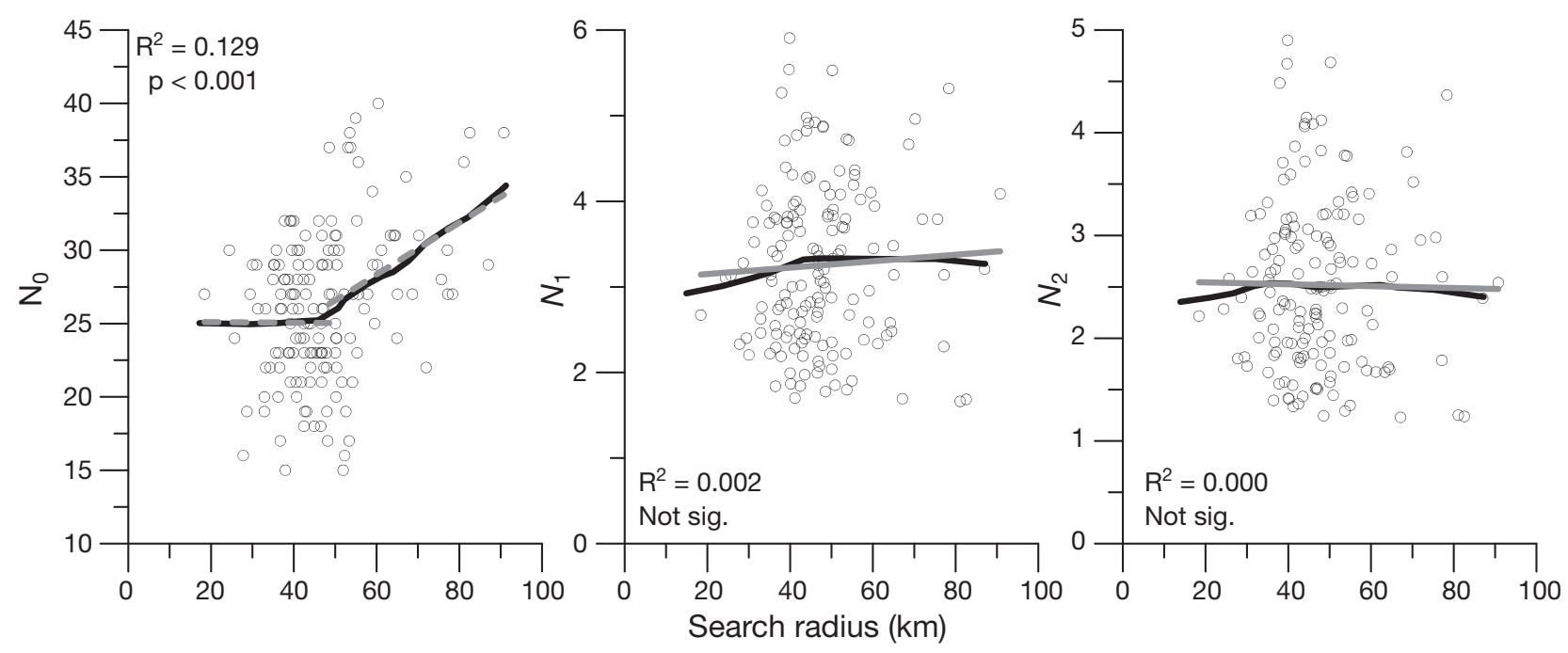

Fig. 9. Effects of ICES rectangle search radius on Hill's $\mathrm{N}_{0}, \mathrm{~N}_{1}$, and $\mathrm{N}_{2}$, calculated on the 20 trawls 'captured' within the search radius aggregated to provide a single rectangle scale species abundance sample. Black curves show Lowess smoother fits to the data (tension $=0.8$; SYSTAT). Grey lines show linear regression fits. On the basis of the shape of the significant Lowess fit to the Hill's $\mathrm{N}_{0}$ data, the species richness fit was split into 2 components (dashed grey line): rectangles for which search radii $\geq 49 \mathrm{~km}$ were required to 'capture' 20 trawl samples, and for which a significant positive relationship $\left(\mathrm{N}_{0}=17.7601+0.1764 D, \mathrm{R}^{2}=0.103\right.$, $\mathrm{p}<0.01)$ to the data was obtained, and rectangles with search radii $<49 \mathrm{~km}$ for which the linear fit was not statistically significant

Furthermore, because Hill's metrics were not believed to be sensitive to a human activity, they were also de facto considered not to be tightly linked in time, or to

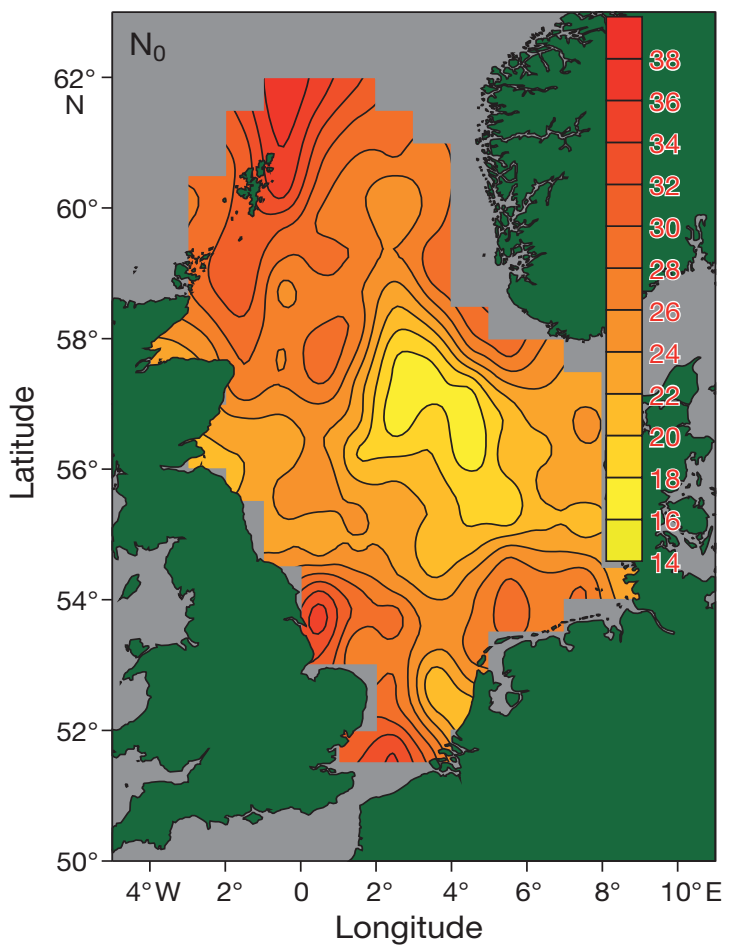

Fig. 10. Spatial variation in species richness (Hill's $\mathrm{N}_{0}$ ) after elimination of the $\beta$-diversity contribution based on the linear regression for $\mathrm{N}_{0}$ from Fig. 9 respond primarily to that activity. Methodological failures in the application of diversity indices have therefore blighted them across several of the ICES criteria. Consequently, in the minds of many marine scientists this precluded the use of diversity indices as state indicators, despite the importance of biodiversity as one of the principal drivers at the heart of the EAM.

In this study, data from the Q3 IBTS were analysed. This is an international survey coordinated through ICES and supported by many countries within and beyond the European Union, particularly those with a fisheries interest in the North Sea. These surveys have operated over at least 2 decades (Heessen 1996, Heessen \& Daan 1996, Piet \& Jennings 2005), and because of their importance to the traditional stock assessment process (ICES 2006), they will no doubt continue to provide the main source of fisheries-independent groundfish abundance data for many years to come. As well as supporting traditional fisheries management, these surveys also provide an important time-series with which to demonstrate the impacts of human activities on the broader fish community, and to monitor the effectiveness of management action to mitigate these. If biodiversity issues are to be addressed directly in future developments of the EAM, then it is crucial that an effective standard methodology for the application of diversity metrics to these IBTS data is established. Determining the level of sample aggregation required, assessing how these samples should be aggregated, and identifying and resolving any other 
issues associated with such sample aggregation are essential components of this.

Cluster analysis revealed spatial zonation in the groundfish community across the North Sea, with different areas being occupied by communities differing in their species composition. Similar zonation has been noted previously (Daan et al. 1990, Fraser et al. 2008). However, our analysis was necessary to ensure that, in examining the influence of sampling effort on the performance of species richness and species diversity indices, each successive sample in the cumulative sample aggregations was drawn from essentially the same community.

Regardless of the aggregation method applied, residuals to the Arrhenius power function fits frequently became increasingly negative at high aggregation levels. Consequently, given previous complete North Sea species inventories (Yang 1982), extrapolation of Arrhenius power function SARs to the ICES rectangle scale produced estimates of species richness that were unrealistically high. Gleason semi-log SARs generally provided the better fit, particularly to the randomised aggregation species richness curves, and extrapolation to the ICES rectangle scale produced more reasonable estimates of species richness. As far as the North Sea groundfish community is concerned, areas as large as an ICES statistical rectangle may be considered 'local' in scale (van der Maarel 1988, Stohlgren et al. 1995). Local resources place a limit on the number of species able to coexist within each rectangle so that the fish communities present are 'saturated': species richness is lower than expected, given the regional species pool (Findley \& Findley 2001, Cottenie et al. 2003, Heino et al. 2003, Kiflawi et al. 2003).

The nested aggregations, particularly when plotted against search radius, suggested multi-phasic species accumulations. These have been noted before (Fridley et al. 2005) and indicate the operation of processes not reflected by either of the 2 SARs (Colwell et al. 2004). The marked effect of search radius suggests that the species richness estimates are increasingly influenced by the inclusion of $\beta$-diversity as new habitats become incorporated within the aggregated sample's search radius. Second-phase increases in species richness accumulation rates occurred at 'search radii' of 40 to $50 \mathrm{~km}$. Even though the aggregations were all carried out within the major community types defined by the cluster analysis at similarity levels of between 65 and $70 \%$, finer-scale clustering at higher similarity levels must still be critical in distinguishing $\beta$ - from $\alpha$-diversity.

In both nested and randomised aggregations, Hill's $\mathrm{N}_{1}$ and $\mathrm{N}_{2}$ stabilised at some stage in the sample aggregation process. At this point, the index values obtained may be considered representative of the community sampled, and so have maximum sensitivity to drivers of change. Both indices are influenced by variation in both species richness and species evenness, so the basic theory underpinning the relationship between species richness and area sampled is contravened (Cam et al. 2002, He \& Legendre 1996, 2002). The 2 SARs could therefore not be applied to Hill's $\mathrm{N}_{1}$ and $\mathrm{N}_{2}$ and extrapolated to estimate species diversity at ICES rectangle scale.

A minimum of 20 IBTS GOV hauls was required to obtain reliable empirical estimates of all 3 metrics. The 'stopping rule' reflected a balance between gains in estimate sensitivity against the economic costs of marine sampling and concerns over the confounding of $\beta$ - and $\alpha$-diversity (see Magurran 2004). The most species-rich areas in the North Sea were adjacent to major inflows - the Fair Isle, East Shetland and Norwegian Trench currents in the North and the English Channel to the south (Turrell 1992, Lenhart et al. 1995) — suggesting that immigration is important in maintaining species richness (e.g. MacArthur \& Wilson 1967, Williamson 1981, Earn et al. 2000). Highest species diversity (both $\mathrm{N}_{1}$ and $\mathrm{N}_{2}$ ) occurred across the central North Sea at the border between 2 major community types. Elements of both community types may have been included in the aggregated samples, thus raising estimates of $\alpha$-diversity. Hill's $\mathrm{N}_{1}$ and $\mathrm{N}_{2}$ appeared robust to the inclusion of $\beta$-diversity as search radius increased, but this was not so for $\mathrm{N}_{0}$. Above search radii of $49 \mathrm{~km}$, estimates of $\alpha$-species richness were increasingly inflated by the inclusion of $\beta$-diversity. However, at a qualitative level, this had little effect on maps of spatial variation in species richness across the North Sea.

While an empirical approach may be the only option with respect to Hill's $N_{1}$ and $N_{2}$, this is not the ideal solution for species richness $\left(\mathrm{N}_{0}\right)$. Empirical estimates of $\mathrm{N}_{0}$ produced a fifth ranking order for the 6 assemblages, similar to the ranking obtained by fitting the Gleason semi-log SAR to randomised aggregations. No single method of ranking species richness of the 6 assemblages corresponded exactly with any of the other methods examined. This begs the question: Why should such a high level of sampling aggregation be required to estimate species richness reliably? Catchability of many demersal fish species in the GOV trawl is low (Fraser et al. 2007). When 'detectability' of species in the sampling gear is poor, species richness metrics are much more strongly influenced by chance events. It becomes more difficult to sample rare species, requiring much greater sampling effort to accurately parameterise SARs and to attain a sufficient sample to rank communities accurately (Boulinier et al. 1998, Cam et al. 2002, Wintle et al. 2004, Mao \& Colwell 2005). 
Hopefully, these analyses will help to establish a recognised methodology for applying species richness and species diversity metrics to groundfish survey data. A standard approach, which takes account of sampling effort requirements, should produce sensitive indices. Once sensitivity has been addressed, species richness and diversity indices should be responsive to drivers of change and more tightly linked in time to such drivers, thereby addressing 3 of the ICES criteria for good state indicators against which these metrics performed so poorly. However, ensuring that metrics are sensitive does not necessarily ensure that they are responsive primarily to human activities, and not responsive to other (e.g. environmental) causes of change. The complexities involved will also do little to reassure scientists that they can easily and accurately be measured with low error rate, and they certainly do not help make such indices easier to understand by policy makers and other nonscientists. Using these metrics within a management context therefore continues to pose some problems.

Previous studies investigated temporal changes in the fish community and thus aggregated samples across space (Greenstreet \& Hall 1996, Greenstreet et al. 1999, Greenstreet \& Rogers 2006). However, spatial issues (marine spatial planning, marine protected areas, etc.) are becoming more important to managers, so questions concerning spatial variation in species richness and diversity were addressed in the present study. To reduce the need for spatial aggregation, data collected over a 7 yr period (1998 to 2004) were aggregated. The environment of the North Sea is changing gradually, and ecosystem-wide changes have occurred (Heath 2005). Consequently, some changes in North Sea groundfish species richness and diversity may have taken place within the time span of this study, but there is no evidence at present of any major 'regime shift' having occurred. Ignoring such a temporal signal when aggregating samples may, at worst, have served to blur the spatial signal. Despite this, however, clear spatial patterns emerged. Documenting variation in $\alpha$ diversity was the main objective. At search radii exceeding $49 \mathrm{~km}$, elements of $\beta$-diversity started to enter the aggregate samples, inflating estimates of $\alpha$-diversity. At current IBTS sampling intensities, obtaining 20 trawl samples from a radius of $49 \mathrm{~km}$ around each ICES rectangle will require the aggregation of data collected over at least 4 yr. From a management perspective, this is not ideal. Following the implementation of any mitigating management action, $12 \mathrm{yr}$ would be required to attain the minimum 3 data points necessary to confirm a new trend. If restoration of biodiversity remains a political objective, then politicians may have to wait longer than usual to reap the political benefits of their actions (see also Nicholson \& Jennings 2004).
Acknowledgements. We thank all our colleagues in the ICES working group on ecosystem effects of fishing activities (WGECO) who have participated in numerous vigorous debates over the years, all of which served to hone the ideas presented here. We are also indebted to colleagues who participated in the MAFCONS project, where these ideas came to final fruition. We also thank staff at ICES who provided the IBTS data. This work was supported by the Scottish executive environment and rural affairs department under ROAMEs MF0753 and MF0168. The MAFCONS (Managing fisheries to conserve groundfish and benthic invertebrate species diversity) project was funded in part by the European Commission (Q5RS-2002-00856). We are indebted to 2 anonymous referees, and to the editor, Jake Rice, whose suggestions greatly improved this paper.

\section{LITERATURE CITED}

Adler PB, Lauenroth WK (2003) The power of time: spatiotemporal scaling of species diversity. Ecol Lett 6:749-756

Adler PB, White EP, Lauenroth WK, Kauffman DM, Rassweiller A, Rusak JA (2005) Evidence for a general species-time-area relationship. Ecology 86:2032-2039

Angermeier PL, Winston MR (1998) Local vs. regional influences on local diversity in stream fish communities of Virginia. Ecology 79:911-927

Boulinier T, Nichols JD, Sauer JR, Hines JE, Pollock KH (1998) Estimating species richness: the importance of heterogeneity in species detectability. Ecology 79:1018-1028

Brose U, Martinez ND, Williams RJ (2003) Estimating species richness: sensitivity to sample coverage and insensitivity to spatial patterns. Ecology 84:2364-2377

Cam E, Nichols JD, Hines JE, Sauer JR, Alpizar-Jara R, Flather CH (2002) Disentangling sampling and ecological explanations underlying species-area relationships. Ecology 83:1118-1130

Chadwick JW, Canton SP (1984) Inadequacy of diversity indices in discerning metal mine drainage effects on a stream invertebrate community. Water Air Soil Pollut 22: $217-223$

Clarke KR, Warwick RM (2001) Change in marine communities: an approach to statistical analysis and interpretation, 2nd edn. PRIMER-E, Plymouth

Colwell RK, Coddington JA (1994) Estimating terrestrial biodiversity through extrapolation. Phil Trans R Soc Lond Ser B 345:101-118

> Colwell RK, Mao CX, Chank J (2004) Interpolating, extrapolating, and comparing incidence-based species accumulation curves. Ecology 85:2717-2727

Cornell HV, Karlson RH (1997) Local and regional processes as controls of species richness. In: Tilman D, Kareiva P (eds) Spatial ecology: the role of space in population dynamics and interspecific interaction. Princeton University Press, Princeton, NJ, p 250-268

Cornell HV, Lawton JH (1992) Species interactions, local and regional processes, and limits to the richness of ecological communities: a theoretical perspective. J Anim Ecol 61: $1-12$

Cottenie K, Michels E, Nuytten N, de Meester L (2003) Zooplankton metacommunity structure: regional vs. local processes in highly interconnected ponds. Ecology 84: 991-1000

> Daan N, Bromley PJ, Hislop JRG, Nielsen NA (1990) Ecology of North Sea fish. Neth J Sea Res 26:343-386

> Denslow JS (1995) Disturbance and diversity in tropical rain forests: the density effect. Ecol Appl 5:962-968 
Earn DJD, Levin SA, Rohani P (2000) Coherence and conservation. Science 290:1360-1364

Findley JS, Findley MT (2001) Global, regional, and local patterns in species richness and abundance of butterfly fishes. Ecol Monogr 71:69-91

Fraser HM, Greenstreet SPR, Piet GJ (2007) Taking account of catchability in groundfish survey trawls: implications for estimating demersal fish biomass. ICES J Mar Sci 64: $1800-1819$

Fraser HM, Greenstreet SPR, Fryer RJ, Piet GJ (2008) Mapping spatial variation in the species diversity and composition of the demersal fish community of the North Sea: taking account of species- and size-related differential catchability in survey trawls. ICES J Mar Sci 65:531-538

Frid CLJ (2003) Managing the health of the seafloor. Frontiers Ecol Environ 1:429-436

Fridley JD, Peet RK, Wentworth TR, White PS (2005) Connecting fine- and broad-scale species-area relationships of southern U.S. Flora. Ecology 86:1172-1177

Garcia SM, Cochrane KL (2005) Ecosystem approach to fisheries: a review of implementation guidelines. ICES J Mar Sci 62:311-318

> Gotelli NJ, Colwell RK (2001) Quantifying biodiversity: procedures and pitfalls in the measurement and comparison of species richness. Ecol Lett 4:379-391

Greenstreet SPR (2008) Biodiversity of North Sea fish: Why do the politicians care but marine scientists appear oblivious to this issue? ICES J Mar Sci 65 (in press)

> Greenstreet SPR, Hall SJ (1996) Fishing and the ground-fish assemblage structure in the north-western North Sea: an analysis of long-term and spatial trends. J Anim Ecol 65:577-598

Greenstreet SPR, Rogers SI (2006) Indicators of the health of the fish community of the North Sea: identifying reference levels for an ecosystem approach to management. ICES J Mar Sci 63:573-593

- Greenstreet SPR, Spence FE, McMillan JA (1999) Fishing effects in northeast Atlantic shelf seas: patterns in fishing effort, diversity and community structure. V. Changes in structure of the North Sea groundfish assemblage between 1925 and 1996. Fish Res 40:153-183

Hadley EA, Maurer BA (2001) Spatial and temporal patterns of species diversity in montane mammal communities of western North America. Evol Ecol Res 3:477-486

Hall SJ, Greenstreet SPR (1996) Diversity, abundance and body size: relationships in the North Sea fish fauna. Nature 383:133

> Hall SJ, Greenstreet SPR (1998) Taxonomic distinctness and diversity measures: responses in marine fish communities. Mar Ecol Prog Ser 166:227-229

He F, Legendre P (1996) On species-area relationships. Am Nat 148:719-737

He F, Legendre P (2002) Species diversity patterns derived from species-area models. Ecology 83:1185-1198

Heath MR (2005) Changes in the structure and function of the North Sea fish foodweb, 1973-2000, and the impacts of fishing and climate. ICES J Mar Sci 62:847-886

Heessen HJL (1996) Time series data for a selection of forty fish species caught during the International Beam Trawl Survey. ICES J Mar Sci 53:1079-1084

Heessen HJL, Daan N (1996) Long-term trends in ten nontarget North Sea fish species. ICES J Mar Sci 53: 1063-1078

- Heino J, Muotka T, Paavola R (2003) Determinants of macroinvertebrate diversity in headwater streams: regional and local influences. J Anim Ecol 72:425-434

Heslenfeld P, Enserink L (2008) OSPAR ecological quality objectives: health indicators for the North Sea. ICES J Mar Sci 65 (in press)

Hill MO (1973) Diversity and evenness: a unifying notation and its consequences. Ecology 54:427-432

ICES (2001) Report of the ICES advisory committee on ecosystems. ICES cooperative research report 249. ICES, Copenhagen

ICES (2006) Report of the working group on the assessment of demersal stocks in the North Sea and Skagerrak (WGNSSK), 6-15 September 2005, ICES Headquarters Copenhagen. ICES CM 2006 ACFM:09

ICES (2007) Report of the working group on ecosystem effects of fishing activities (WGECO). ACE:04

Jennings S, Reynolds JD (2000) Impacts of fishing on diversity: from pattern to process. In: Kaiser MJ, de Groot B (eds) Effects of fishing on non-target species and habitats: biological, conservation and socio-economic issues. Blackwell Science, Oxford, p 235-250

Jennings S, Greenstreet SPR, Reynolds J (1999) Structural change in an exploited fish community: a consequence of differential fishing effects on species with contrasting life histories. J Anim Ecol 68:617-627

> Jennings S, Greenstreet SPR, Hill L, Piet GJ, Pinnegar JK, Warr KJ (2002) Long-term trends in the trophic structure of the North Sea fish community: evidence from stable isotope analysis, size spectra and community metrics. Mar Biol 141:1085-1097

Johnson D (2008) Environmental indicators: their utility in meeting the OSPAR convention's regulatory needs. ICES J Mar Sci 65 (in press)

Keating KA, Quinn JF (1998) Estimating species richness: the Michaelis-Menton model revisited. Oikos 81:411-416

Keating KA, Quinn JF, Ivie MA, Ivie LL (1998) Estimating the effectiveness of further sampling in species inventories. Ecol Appl 8:1239-1249

> Kiflawi M, Spencer M (2004) Confidence intervals and hypothesis testing for beta diversity. Ecology 85: 2895-2900

Kiflawi M, Eitam A, Blaustein L (2003) The relative impact of local and regional processes on macro-invertebrate species richness in temporary pools. J Anim Ecol 72:447-452

> Lande R (1996) Statistics and partitioning of species diversity, and similarity among multiple communities. Oikos 76 : $5-13$

Lenhart HJ, Radach G, Backhaus JO, Pohlmann T (1995) Simulations of the North Sea circulation, its variability, and its implementation as hydrodynamical forcing in ERSEM. Neth J Sea Res 33:271-299

MacArthur RH, Wilson EO (1967) The theory of island biogeography. Princeton University Press, Princeton, NJ

Magurran AE (1988) Ecological diversity and its measurement. Chapman \& Hall, London

Magurran AE (2004) Measuring biological diversity. Blackwell Publishing, Oxford

$>$ Magurran AE (2007) Species abundance distributions over time. Ecol Lett 10:347-354

Mao CX, Colwell RK (2005) Estimation of species richness: mixture models, the role of rare species, and inferential challenges. Ecology 86:1143-1153

Nicholson MD, Jennings S (2004) Testing candidate indicators to support ecosystem-based management: the power of monitoring surveys to detect temporal trends in fish community metrics. ICES J Mar Sci 61:35-42

> O'Hara RB (2005) Species richness estimators: How many species can dance on the head of a pin? J Anim Ecol 74:375-386

> Palmer MW (1988) Fractal geometry: a tool for describing spatial patterns of plant communities. Vegetatio 75:91-102 
Palmer MW (1990) The estimation of species richness by extrapolation. Ecology 71:1195-1198

Piet GJ, Jennings S (2005) Response of potential fish community indicators to fishing. ICES J Mar Sci 62:214-225

Rice J, Gislason H (1996) Patterns of change in the size spectra of numbers and diversity of the North Sea fish assemblage, as reflected in surveys and models. ICES J Mar Sci 53:1214-1225

Rice JC, Rochet MJ (2005) A framework for selecting a suite of indicators for fisheries management. ICES J Mar Sci 62: 516-527

Rijnsdorp AD, Leeuwen PIv, Daan N, Heessen HJL (1996) Changes in the abundance of demersal fish species in the North Sea between 1906-1909 and 1990-1995. ICES J Mar Sci 53:1054-1062

Robinson JV, Sandgren CD (1984) An experimental evaluation of diversity indices as environmental discriminators. Hydrobiologia 108:187-196

Rogers SI, Ellis JR (2000) Changes in the demersal fish assemblages of British coastal waters during the 20th century. ICES J Mar Sci 57:866-881

Rogers SI, Maxwell D, Rijnsdorp AD, Damm U, Vanhee W (1999) Fishing effects in northeast Atlantic shelf seas: patterns in fishing effort, diversity and community structure. IV. Can comparisons of species diversity be used to assess human impacts on demersal fish faunas? Fish Res 40: 135-152

Rosenzweig ML (1995) Species diversity in space and time. Cambridge University Press, Cambridge

Shurin JB (2007) How is diversity related to species turnover through time? Oikos 116:957-965

Soberón JM, Llorente JB (1993) The use of species accumulation functions for the prediction of species richness. Conserv Biol 7:480-488

Soetaert K, Heip C (1990) Sample-size dependence of diversity indices and the determination of sufficient sample size in a high-diversity deep-sea environment. Mar Ecol Prog Ser 59:305-307

Sokal RR, Rohlf FJ (1981) Biometry, 2nd edn. WH Freeman, San Francisco, CA

Editorial responsibility: Jake Rice,

Ottawa, Canada
Southwood TRE (1978) Ecological methods: with particular reference to the study of insect populations. Chapman \& Hall, London

Stohlgren TJ, Falkener MB, Schell LD (1995) A modifiedWhittaker nested vegetation sampling method. Vegetatio 117:113-121

Storch D, Sizling AL, Gaston KJ (2003) Geometry of the species-area relationship in central European birds: testing the mechanism. J Anim Ecol 72:509-519

Turrell WR (1992) New hypotheses concerning the circulation of the northern North Sea and its relation to North Sea fish stock recruitment. ICES J Mar Sci 49:107-123

Ugland KI, Gray JS, Ellingsen KE (2003) The species-accumulation curve and estimation of species richness. J Anim Ecol 72:888-897

van der Maarel E (1988) species diversity in plant communities in relation to structure and dynamics. In: During HJ, Werger MJA, Willems HJ (eds) Diversity and pattern in plant communities. SPB Academic, The Hague, p 1-14

van Gemerden BS, Etienne RS, Olff H, Hommel PWFM, van Langevelde F (2005) Reconciling methodologically different biodiversity assessments. Ecol Appl 15:1747-1760

> Washington HG (1984) Diversity, biotic and similarity indices: a review with special relevance to aquatic ecosystems. Water Res 18:653-694

White EP, Adler PB, Lauenroth WK, Gill RA and others (2006) A comparison of the species-time relationship across ecosystems and taxonomic groups. Oikos 112:185-195

> Whittaker RH (1972) Evolution and measurement of species diversity. Taxon 21:213-251

Williamson MH (1981) Island populations. Oxford University Press, Oxford

Wintle BA, McCarthy MA, Parris KM, Burgman MA (2004) Precision and bias of estimates for estimating point survey detection probabilities. Ecol Appl 14:703-712

- Wright JP, Flecker AS, Jones CG (2003) Local vs. landscape controls on plant species richness in beaver meadows. Ecology 84:3162-3173

Yang J (1982) The dominant fish fauna in the North Sea and its determination. J Fish Biol 20:635-643

Submitted: October 24, 2007; Accepted: March 25, 2008

Proofs received from author(s): July 10, 2008 